\title{
Self-assembly characteristics of a multipolar donor-acceptor-based bis-pyrene integrated molecular tweezer
}

\author{
DEEPAK ASTHANA, GEETA HUNDAL and PRITAM MUKHOPADHYAY* \\ Supramolecular \& Material Chemistry Lab, School of Physical Sciences, Jawaharlal Nehru University, \\ New Delhi 110067, India \\ e-mail: m_pritam@jnu.ac.in
}

MS received 10 April 2014; revised 02 June 2014; accepted 01 July 2014

\begin{abstract}
A modular design of a molecular tweezer is presented that integrates a multipolar D- $\pi$-A [D: Donor, A: Acceptor] scaffold, 1-aminopyrene-based fluorophore units and L-alanine-based linkers. The synthesis of the molecule is based on two-fold aromatic nucleophilic reactions $\left(\mathrm{ArS}_{\mathrm{N}}\right)$ and coupling reactions of the acid and amino functionalities. This molecule crystallizes in a non-centrosymmteric (P21) space group. We present its rich self-assembly characteristics that involves an array of $\pi$-stacking interactions. In addition, the molecular tweezer within its cleft forms H-bonding with two dimethylformamide molecules. Such multipolar D- $\pi$-A systems containing chiral and fluorophore units are potential candidatesfor a number of electronic and photonic applications.
\end{abstract}

Keywords. Amino-pyrene; pi-conjugated systems; supramolecular self-assembly; molecular electronics; fluorescent probes and chemosensors.

\section{Introduction}

In search of smart molecular electronic devices, $\pi$ conjugated systems have drawn special attention. These have been applied as building blocks to develop new classes of multi-responsive electronic materials. Supramolecular self-assembly of planar $\pi$-conjugated systems ${ }^{1 a}$ represent one of the most frequently applied design strategies for construction of functional organic nano-devices. ${ }^{1 \mathrm{~b}}$

In this context, pyrene derived molecular systems are of major interest towards designing organic electronic devices, for example, sensors, dye sensitized solar cells, light emitting diodes, semiconductors, etc., ${ }^{2,3}$ Pyrene moiety has also been integrated with a variety of molecular scaffolds to generate nano-architectures like supramolecular capsules, emissive nanofibers, nanotubes, etc. ${ }^{4}$ In addition to their electronic properties, pyrene-based materials find applications in a number of biological processes such as in cell imaging, structural study of proteins, peptides, lipid membranes, temperature sensors, etc. ${ }^{5}$ Most of these properties rely on weak supramolecular interactions and their diverse packing modes. More specifically, 1-aminopyrene and its electronic properties, photophysical properties, excitation

*For correspondence dynamics, light harvesting, etc., ${ }^{6}$ has been the topic of recent interest.

In our group, we have been interested in designing molecular systems that can utilize D-A based interactions to undergo selective electron transfer (ET) reactions and produce paramagnetic radical ion probes. ${ }^{7}$ Also, we have shown that supramolecular interactions can be used to modulate non-linear optical (NLO) ${ }^{8}$ and ferroelectric properties ${ }^{9}$ of $\mathrm{D}-\pi$-A-based molecules. The $\pi-\pi$ stacking interactions play an important role in determining the effective properties of these materials.

Herein, we have designed a molecular tweezer that integrates a multipolar $\mathrm{D}-\pi-\mathrm{A}$ building block, two aminopyrene-based fluorophore units and two Lalanine-based linkers (scheme 1). The synthesis of the molecule was based on two-fold aromatic nucleophilic reactions $\left(\mathrm{ArS}_{\mathrm{N}}\right)$ and coupling reaction of the acid and amino functionalities. We present its rich self-assembly characteristics ${ }^{10}$ that exhibits threedimensional network formation through $\pi-\pi$ stacking interactions and its trapping of dimethylformamide molecules.

In essence, the molecule constitutes a multipolar D$\pi$-A unit, H-bonding encapsulating units, chiral units and fluorophore units. This should make the molecule and the self-assembled structure multi-responsive to a variety of stiumulus. 


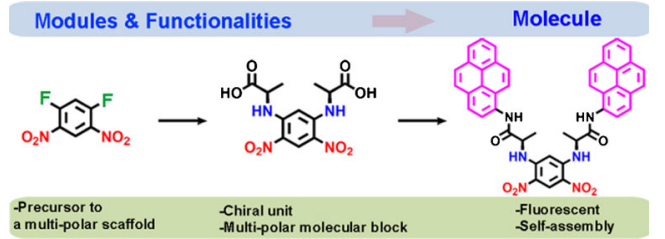

Scheme 1. Scheme showing modular design of 1 .

\section{Experimental}

\subsection{Materials and physical measurements}

Chemicals 1-aminopyrene, 1,5-difluor-2,4-dinitro benzene and L-alanine were obtained from Sigma Aldrich and were used as received. Thin layer chromatography (TLC) was carried out on aluminium plates coated with silica gel mixed with fluorescent indicator having particle size of $25 \mu \mathrm{m}$ and was sourced from Merck India. ${ }^{1} \mathrm{H}$ and ${ }^{13} \mathrm{C}$ NMR spectra were recorded on a Bruker $500 \mathrm{MHz}$ spectrometer in DMSO- $d_{6}$ with TMS as standard. Infra-Red spectra were recorded in $\mathrm{KBr}$ pellet using Varian 3100 FT-IR instrument. MALDI-TOF mass spectral data was obtained using a Bruker made Autoflex TOF/TOF instrument and $\alpha$-Cyano-4-hydroxycinnamic acid as the matrix. InfraRed spectrum was recorded in $\mathrm{KBr}$ pellets using a Varian 7000 FT-IR instrument. The UV-vis absorption spectrum was taken in dichloromethane (DCM) solvent using a JASCO V-600 model spectrometer. The steady state fluorescence spectrum was measured in DCM using a Varian Cary Eclipse Fluorescence Spectrometer.

\subsection{Design and synthesis}

Our molecular design utilizes a 1,5-difluoro-2,4-dinitro benzene as the precursor unit in order to integrate the two aminopyrene groups with the L-alanine spacers (scheme 1). Compound 1 was synthesized in two simple steps and was fully characterized by various analytical techniques such as mass, NMR and IR spectroscopy (Supplementary Information). The starting material bisalanine functionalized derivative of 1,5-difluoro-2,4dinitro benzene (1a) was obtained by following a previously reported method, ${ }^{11}$ which was then further reacted with 1-aminopyrene in dichloromethane in the presence of $N, N$ '-dicyclohexylcarbodiimide (DCC), 4(dimethylamino)pyridine (DMAP) and hydroxybensotriazole (HOBt) under reflux conditions (scheme 2). To obtain molecule 1a, reagents 1,5-difluoro-2,4-dinitro benzene $(0.75 \mathrm{~g}, 3.7 \mathrm{mmol})$, L-alanine $(0.65 \mathrm{~g}, 7.3 \mathrm{mmol})$ and sodium carbonate $(0.78 \mathrm{~g}, 7.4 \mathrm{mmol})$ were mixed in a $100 \mathrm{~mL}$ round bottomed flask containing $30 \mathrm{~mL}$ of $50 \% \mathrm{EtOH}$. The mixture was stirred and then initially heated upto $50^{\circ} \mathrm{C}$ for 30 minutes and then at $60^{\circ} \mathrm{C}$ for next 10 minutes. Reaction mixture was then cooled down to $10^{\circ} \mathrm{C}$. Solvent was evaporated using rotary evaporator and obtained solid was washed with $\mathrm{EtOH}$. The residue was neutralized with $5 \mathrm{~N} \mathrm{HCl}$ to yield $850 \mathrm{mg}$ of 1a. In the next step molecule $1 \mathbf{a}(0.26 \mathrm{~g}, 0.7 \mathrm{mmol})$ was taken with DMAP $(0.66 \mathrm{~g}, 3.2 \mathrm{mmol})$ in $30 \mathrm{~mL}$ of dry dichloromethane and stirred for 15 minutes under inert atmosphere at $0^{\circ} \mathrm{C}$. To the stirred mixture 1aminopyrene $(0.4 \mathrm{~g}, 1.8 \mathrm{mmol})$ was added followed by the subsequent addition of DCC $(0.66 \mathrm{~g}, 3.2 \mathrm{mmol})$ and HOBt $(0.26 \mathrm{~g}, 1.7 \mathrm{mmol})$ into the ice cooled reaction mixture and continued the stirring for $15 \mathrm{~h}$ with gradual heating up to room temperature. The crude product was purified by performing column chromatography. ${ }^{1} \mathrm{H}-\mathrm{NMR}$ (DMSO- $d_{6}, 294 \mathrm{~K}, \mathrm{ppm}$ ): $\delta 10.41$ $(2 \mathrm{H}$, PyNHCO), $9.12(\mathrm{~s}, 1 \mathrm{H}$, dinitrobenzene $\mathrm{CH})$, 9.08-9.05 (2H), 8.33-8.09 (18H, РуCH), $6.06(1 \mathrm{H}$, dinitrobenzene $\mathrm{CH}), 4.81\left(2 \mathrm{H}, \mathrm{CH}_{3} \mathrm{CH}\right), 1.80(6 \mathrm{H}$, $\left.\mathrm{CH}_{3}\right) .{ }^{13} \mathrm{C}-\mathrm{NMR}$ (DMSO- $d_{6}, 294 \mathrm{~K}, \mathrm{ppm}$ ): $\delta 171.8$, $147.4,131.2,131.1,130.9,130.8,129.4,129.2$, $128.8,127.9,127.7,127.5,127.0,126.0,125.7,125.5$, 125.3, 124.8, 124.7, 124.6, 124.2, 122.6, 115.7, 115.6, 92.5, 53.2, 19.0. MALDITOF mass $(\mathrm{m} / \mathrm{z})$ calculated $\mathrm{C}_{44} \mathrm{H}_{32} \mathrm{~N}_{6} \mathrm{O}_{6}$ : 740.8 , found 740.9 .

\section{$2.3 X$-ray crystallography}

$\mathrm{X}$-ray quality crystals of molecule $\mathbf{1}$ were grown from $\mathrm{DMF} / \mathrm{CHCl}_{3}$ (1:1.3) solvent mixture by slow evaporation method at room temperature. The reported data set was collected by mounting the crystal with paratone oil at $100 \mathrm{~K}$, on a Bruker's Apex-II CCD diffractometer using $\mathrm{Mo} \mathrm{K} \alpha(\lambda=0.71069 \AA)$. The data were corrected for Lorentz and polarization effects and empirical absorption corrections were applied using 01SADABS from Bruker. The number of total, independent and observed reflections ([I>2 $\sigma(\mathrm{I})]$ for theta $25^{\circ}$ ) were $24405,11089,7544$. The structures were solved by direct methods using SIR-92 and refined by full-matrix least squares refinement methods based on $\mathrm{F}^{2}$, using SHELX-97.

\section{Results and Discussions}

\subsection{Optical properties}

Absorption and emission properties are of major importance while designing materials for sensing, photonic and light harvesting applications. ${ }^{12}$ Pyrene moiety is 

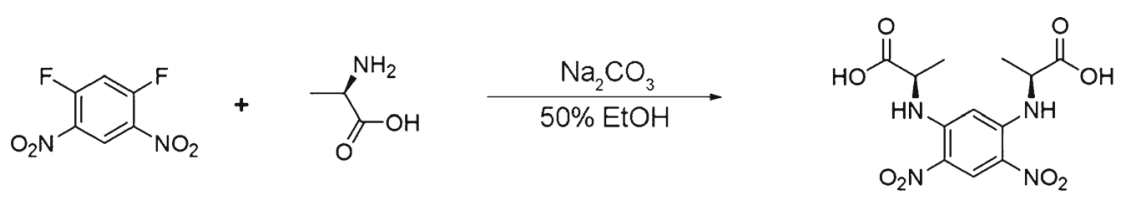

$1 a$

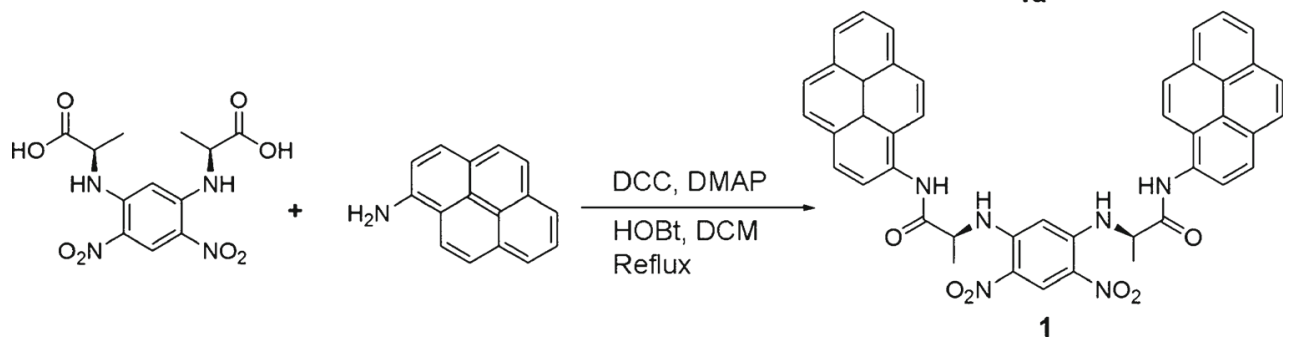

Scheme 2. Synthetic steps and conditions for preparation of $\mathbf{1}$.

known for its high quantum yield and excimer emission properties and therefore pyrene derivatives represent a class of materials with exciting optical properties. ${ }^{13}$

Dichloromethane solution of molecule 1 shows absorption around $345 \mathrm{~nm}$ and a shoulder peak at $400 \mathrm{~nm}$ (figure 1). Emission spectrum of molecule 1 (figure 1, blue spectrum) in dichloromethane solvent shows typical emission between $370-520 \mathrm{~nm}$ with major intensity at $410 \mathrm{~nm}$.

However, if pyrene moiety in excited state is close to ground state pyrene ring $(\sim 10 \AA)$ the interaction between such pairs can result in excimer emission. ${ }^{13 a, 14}$

\subsection{Crystal structure}

Molecule 1 crystallizes into a monoclinic system with a non-centrosymmetric space group $\mathrm{P} 2_{1}$, which falls in one of the ten polar point groups (table 1).

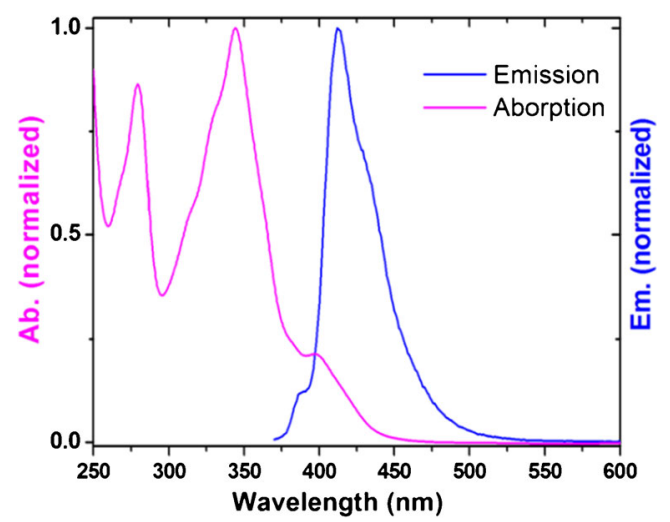

Figure 1. Absorption and emission spectrum of molecule 1 in dichloromethane.
Crystallization in a polar point group is a necessary condition for applications such as ferroelectricity and related properties like piezoelectricity, pyroelectricity and non-linear optical activity. ${ }^{15}$ Single crystal X-ray data reveals a unit cell containing two molecules in each unit (figure S2). The two pyrene groups in the molecule are expanded in space to impart a 'V-type structure' (figure 2). This excludes the possibilities of formation of molecular clip type arrangement in which two pyrene groups face each other.

Two $N, N^{\prime}$-dimethylformamide (DMF) solvent molecules (figure S1 \& S2) form intermolecular hydrogen bonds (H-bonds) with two pyrene $\mathrm{N}-\mathrm{H}$ groups (figure 2). The H-bonding parameters are dissimilar. The $\mathrm{O}-\mathrm{H}$ distances are $1.99 \AA$ and $2.20 \AA$ respectively, whereas, $\mathrm{O}-\mathrm{N}$ distances are $2.85 \AA$ and $3.02 \AA$ and $\mathrm{N}-\mathrm{H}-\mathrm{O}$ angles are at $172.4^{\circ}$ and $160.3^{\circ}$ respectively. This suggests one DMF molecule to be bound more tightly than the other.

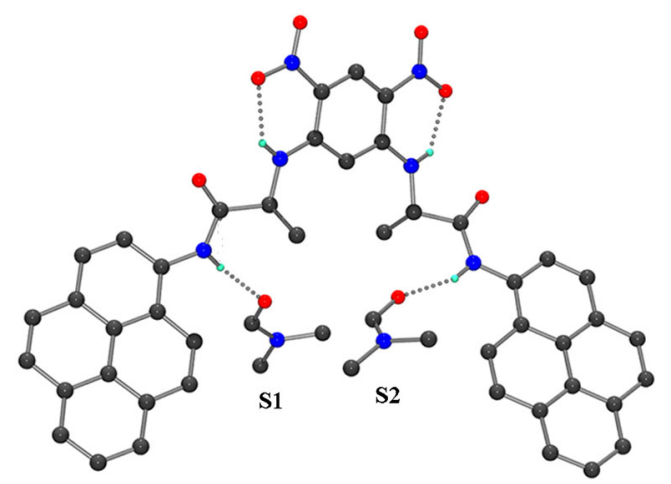

Figure 2. Hydrogen bonding pattern with the two DMF molecules. H-atoms which are involved in hydrogen bonding are shown for clarity. 
Table 1. Crystal data of $\mathbf{1}$

\begin{tabular}{|c|c|}
\hline Empirical formula & $\begin{array}{l}\mathrm{C}_{50} \mathrm{H}_{46} \mathrm{~N}_{8} \mathrm{O}_{8} \\
886.95\end{array}$ \\
\hline Formula weight & $100(2) \mathrm{K}$ \\
\hline Temperature & $0.71073 \AA$ \\
\hline Wavelength & Monoclinic \\
\hline Crystal system & $\mathrm{P} 21$ \\
\hline Space group & $\mathrm{a}=13.3490(8) \AA$ \\
\hline Unit cell & $\alpha=90^{\circ}$ \\
\hline dimensions & $\begin{array}{l}\mathrm{b}=11.6327(7) \AA \\
\beta=93^{\circ} \\
\mathrm{c}=13.7654(6) \AA\end{array}$ \\
\hline Volume & $\gamma=90^{\circ}$ \\
\hline $\mathrm{Z}$ & $2134.4 \AA^{3}$ \\
\hline Density calculated & 2 \\
\hline Absorption & $1.380 \mathrm{Mg} / \mathrm{m}^{3}$ \\
\hline coefficient & $0.096 \mathrm{~mm}^{-1}$ \\
\hline $\mathrm{F}(000)$ & 932 \\
\hline Crystal Size & $0.28 \times 0.20 \times 0.14$ \\
\hline Theta range for & $\mathrm{mm}^{3}$ \\
\hline data collection & 1.48 to $29.46^{\circ}$ \\
\hline Reflections collected & 24405 \\
\hline Independent & 11089 \\
\hline reflections & {$[\mathrm{R}(\mathrm{int})=0.065]$} \\
\hline Refinement method & $\begin{array}{l}\text { Full-matrix least-squares } \\
\text { on } \mathrm{F}^{2}\end{array}$ \\
\hline Data/restraints/parameters & $11089 / 1 / 633$ \\
\hline Goodness-of-fit on $\mathrm{F}^{2}$ & 0.901 \\
\hline Final R & $\mathrm{R} 1=0.0593$ \\
\hline indices $[\mathrm{I}>\operatorname{sigma}(\mathrm{I})]$ & $\mathrm{wR} 2=0.1318$ \\
\hline $\mathrm{R}$ indices (all data) & $\mathrm{R} 1=0.0982$ \\
\hline Absolute structure & $\mathrm{wR} 2=0.1584$ \\
\hline parameter & $-0.6(11)$ \\
\hline Largest diff. peak \& hole & 0.304 and $-0.243 \mathrm{e}^{-3}$ \\
\hline CCDC & 996279 \\
\hline
\end{tabular}

\subsection{Supramolecular network}

The single-crystal structure shows formation of extended supramolecular chains through stacking interactions between the diamino- dinitrobenzene and the electron rich pyrene units (figure 3). There is no $\mathrm{H}$ bonding interaction along the molecular chain (b-axis) and therefore $\pi-\pi$ stacking interactions play crucial role in the network formation.

Molecules pack in such a way that diaminodinitrobenzene of one molecule faces the pyrene group of other and so on (figure 3a-b). As shown in figure $3 b$ the 1,5-dinitrobenzene moiety is sandwiched between two pyrene groups from different molecules in the chain. Centroid-centroid distance between two stacked pyrene-dinitrobenzene moieties is $3.90 \AA$ and $7.74 \AA$ (figure $3 \mathrm{a}$ ). As the molecule $\mathbf{1}$ is a rigid system, the

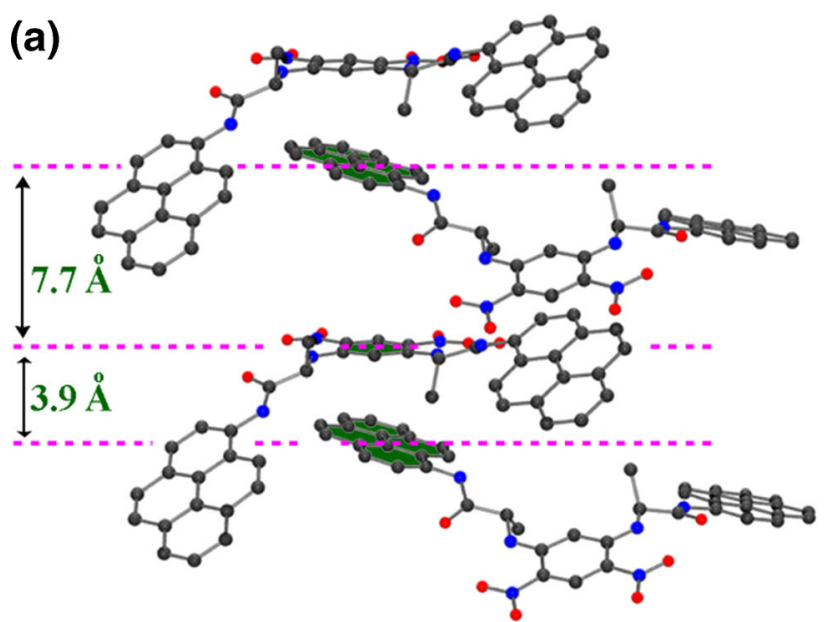

(b)

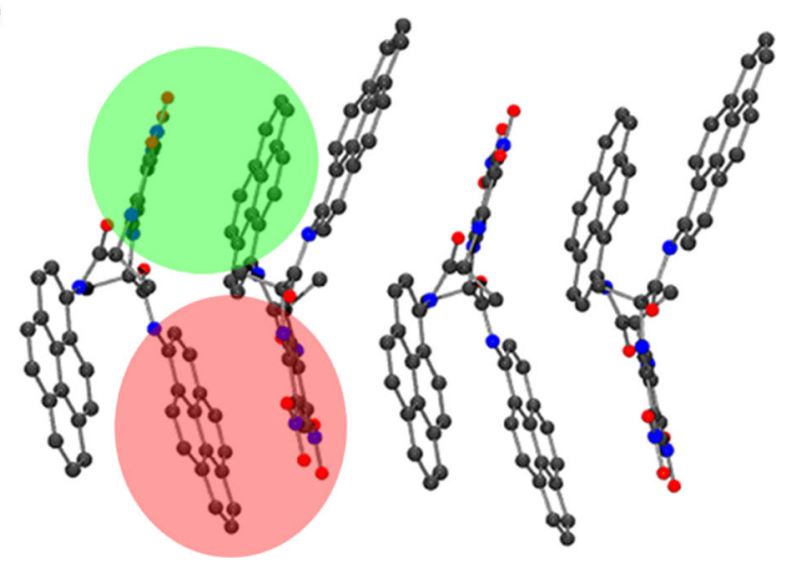

Figure 3. Ortep (POV-ray) diagrams ( $\mathrm{a} \& \mathrm{~b}$ ) showing $\pi-\pi$ stacks leading to a 1-dimensional molecular chain formation along the b-axis.

central molecule adjusts its orientation in a way to facilitate stacking interactions (shown in green circle). This arrangement finally leads to formation of a supramolecular molecular chain. These one dimensional molecular chains further pack along a-axis to form a 2dimensional network (figure 4a). These structures form 3-dimensional network as shown in figure $4 \mathrm{~b}$. As can be seen, dinitrobenzene rings are sandwiched between aminopyrene rings and come exactly over one-another resulting in a nicely packed arrangement of pyrene rings.

We anticipate that the strict compliance of the symmetry constraints by this modular molecule i.e., its favourable polar arrangement would be highly significant for its futuristic applications as NLO and ferroelectric materials. ${ }^{16}$ Furthermore, the integrated multiple units would bestow a high degree of stimuli responsiveness. ${ }^{17}$ 
(a)

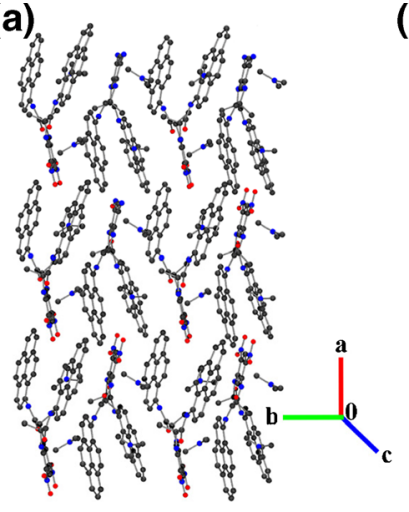

(b)

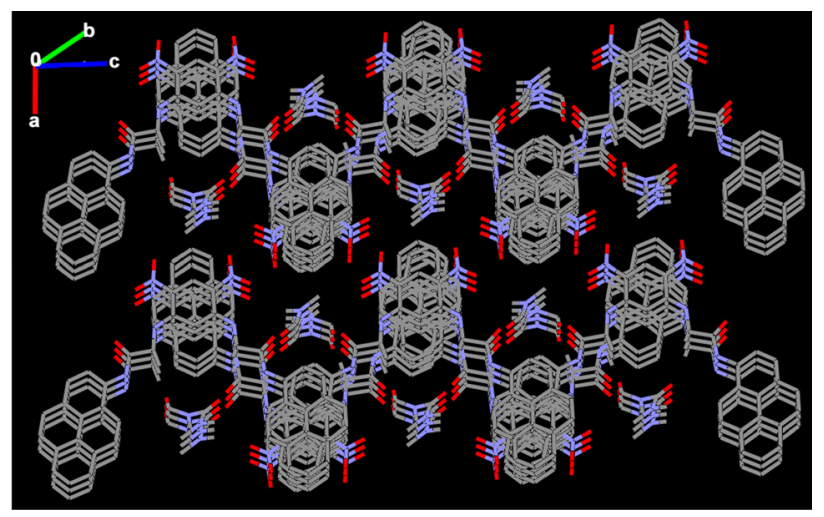

Figure 4. (a) POV-ray diagram of two-dimensional network and (b) three dimensional self-assembly of molecule.

\section{Conclusions}

We have designed and synthesized a modular molecule which constitutes a multipolar D- $\pi$-A unit, H-bonding groups, encapsulating unit, chiral centres and fluorophore units. The molecule crystallizes in one of the ten polar point groups satisfying the symmetry prerequisites for a number of important material properties such as NLO, ferroelectricity, piezoelectricity, etc. We have demonstrated the supramolecular self-assembly characteristics of this molecule in the solid state.

\section{Supplementary Information}

The detailed procedure for synthesis and characterization, MALDITOF Mass, IR, ${ }^{1} \mathrm{H}$ and ${ }^{13} \mathrm{C}$, DEPT-135, APT NMR spectra, X-ray crystallographic tables are given in SI file available at www.ias.ac.in/chemsci.

\section{Acknowledgements}

We acknowledge DBT BUILDER, DST PURSE for the funding and the central instrumentation facility at AIRF, JNU for IR, Mass and NMR studies.

\section{References}

1. (a) Hoeben F J M, Jonkheijm P, Meijer E W and Schenning A P H J 2005 Chem. Rev. 105 1491; (b) Zang L, Che Y and Moore J S 2008 Acc. Chem. Res. 411596

2. (a) Wang L, Li W, Lu J, Zhao Y-X, Fan G, Zhang J-P and Wang H 2013 J. Phys. Chem. C 117 26811; (b) Ding L, Liu Y, Cao Y, Wang L, Xin Y and Fang Y 2012 J. Mater. Chem. 22 11574; (c) Nishizawa S, Kato Y and Teramae N 1999 J. Am. Chem. Soc. 121 9463; (d) Wang M, Xu J, Liu X and Wang H 2013 New J. Chem. 37 3869; (e) Ingale S A and Seela F 2012 J. Org. Chem. 77 9352; (f) Zhou Y, Zhu C-Y, Gao X-S, You X-Y and Yao C 2010 Org. Lett. 12 2566; (g) Cho H, Lee S, Cho N S, Jabbour G E, Kwak J, Hwang D-H and Lee C 2013 ACS Appl.
Mater. Interfaces 5 3855; (h) Zhang H, Wang Y, Shao K, Liu Y, Chen S, Qiu W, Sun X, Qi T, Ma Y, Yu G, Su Z and Zhu D 2006 Chem. Commun. 755; (i) Wu N-W, Zhang J, Ciren D, Han Q, Chen L-J, Xu L and Yang H-B 2013 Organometallics 322536

3. Figueira-Duarte T M and Müllen K 2011 Chem. Rev. 1117260

4. (a) Vybornyi M, Rudnev A V, Langenegger S M, Wandlowski T, Calzaferri G and Häner R 2013 Angew. Chem. Int. Ed. 52 11488; (b) Wang M, Xu J, Liu X and Wang H 2013 New J. Chem. 37 3869; (c) Tang H, Oliveira C S de, Sonntag G, Gibb C L D, Gibb B C and Bohne C 2012 J. Am. Chem. Soc. 134 5544; (d) Li W, Wang L, Zhang J-P and Wang H 2014 J. Mater. Chem. C 21887

5. (a) Winnik F M 1993 Chem. Rev. 93 587; (b) Goedeweeck M, Auweraer M V der and Schryver F C De 1985 J. Am. Chem. Soc. 107 2334; (c) Song X and Swanson B I 1999 Langmuir 15 4710; (d) Sahoo D, Narayanaswamy V, Kay C M and Ryan R O 2000 Biochemistry 39 6594; (e) Lewis F D, Zhang Y and Letsinger R L 1997 J. Am. Chem. Soc. 1195451

6. (a) Chen Z, Lohr A, Saha-Möller C R and Würthner F 2009 Chem. Soc. Rev. 38 564; (b) Zhang L, Liu C, Jin Q, Zhu X and Liu M 2013 Soft Matter 97966

7. (a) Ajayakumar M R, Hundal G and Mukhopadhyay P 2013 Chem. Commun. 49 7684; (b) Ajayakumar M R, Asthana D and Mukhopadhyay P 2012 Org. Lett. 14 4822; (c) Ajayakumar M R and Mukhopadhyay P 2010 Org. Lett. 12 2646; (d) Ajayakumar M R and Mukhopadhyay P 2009 Chem. Commun. 3702

8. (a) Asthana D, Pandey R and Mukhopadhyay P 2013 Chem. Commun. 49 451; (b) Mukhopadhyay P, Bharadwaj P K, Krishnan A and Das P K 2002 J. Mater. Chem. 12 2786; (c) Mukhopadhyay P, Bharadwaj P K, Savitha G, Krishnan A and Das P K 2002 J. Mater. Chem. 12 2237; (d) Mukhopadhyay P, Bharadwaj P K, Savitha G, Krishnan A and Das P K 2000 Chem. Commun. 1815

9. Asthana D, Kumar A, Pathak A, Sukul P K, Malik S, Chatterjee R, Patnaik S, Rissanen K and Mukhopadhyay P 2011 Chem. Commun. 478928

10. (a) Lehn J-M 1995 In Supramolecular Chemistry: Concepts and Perspectives (Weinheim: Wiley-VCH) p 1-271; (b) Desiraju G R 1996 In Perspectives in Supramolecular Chemistry: The Crystal as a Supramolecular Entity Vol 2 (Chichester: Wiley) 
11. Feuer H, Bachmann G B and Kispersky J P 1951 J. Am. Chem. Soc. 733575

12. (a) Martínez-Mánẽz R and Sancenón F 2003 Chem. Rev. 103 4419; (b) Kim S K, Bok J H, Bartsch R A, Lee J Y and Kim J S 2005 Org. Lett. 7 4839; (c) Liao J-H, Chen C-T and Fang J-M 2002 Org. Lett. 4 561; (d) Wang L, Li W, Lu J, Zhang J-P, Wang H 2014 Tetrahedron 70 3172; (e) Kim H J, Kim S K, Lee J Y and Kim J S 2006 J. Org. Chem. 71 6611; (f) Lu H, Wang Q, Li Z, Lai G, Jiang J and Shen Z 2011 Org. Biomol. Chem. 9 4558; (g) Ziessel R, Ulrich G, Haefele A and Harriman A 2013 J. Am. Chem. Soc. 135 11330; (h) Zaragoza-Galán G, Fowler M, Rein R, Solladiá N, Duhamel J and Rivera E 2014 J. Phys. Chem. C 1188280

13. (a) Kaafarani B R, El-Ballouli A O, Trattnig R, Fonari A, Sax S, Wex B, Risko C, Khnayzer R S, Barlow S, Patra D, Timofeeva T V, List E J W, Brédase J-L and Marder S R 2013 J. Mater. Chem. C 1 1638; (b) Bains G K, Kim S H, Sorin E J and Narayanaswami V 2012 Biochemistry 51 6207; (c) Zhang L, Liu C, Jin Q, Zhua X and Liu M 2013 Soft Matter 9 7966; (d) Ding L, Liu Y, Cao Y, Wang L, Xin Y and Fang Y 2012 J. Mater. Chem. 22 11574; (e) Aguilar-Martínez M, Bautista-Martínez $\mathrm{J}$ A and Rivera E 2008 Designed Monomers and Polymers 11 173; (f) Liu X-T, Zhao Y, Ren A-M and Feng J-K 2011 J. Mol. Model. 17 1413; (g) Nakamura M, Fukunaga Y, Sasa K, Ohtoshi Y, Kanaori K, Hayashi H, Nakano H and Yamana K 2005 Nucleic Acids Res. 335887
14. (a) Birks J B 1970 In Photophysics of aromatic molecules (New York: Wiley-Interscience); (b) Birks J B and Christophorou L G 1963 Spectrochimica Acta 19 401; (c) Smalley M K and Silverman S K 2006 Nucleic Acids Res. 34 152; (d) Li M-C, Ho R-M and Lee Y-D 2011 J. Mater. Chem. 21 2451; (e) Nakamura M, Fukuda M, Takada T and Yamana K 2012 Org. Biomol. Chem. 10 9620

15. (a) Klapper H and Hahn Th 2002 Point Group Symmetry and Physical Properties of Crystals: International Tables for Crystallography A 804; (b) Braga D, Grepioni F and Desiraju G R 1998 Chem. Rev. 98 1375; (c) Halasyamani P S and Poeppelmeier K R 1998 Chem. Mater. 102753

16. (a) Sagara Y, Mutai T, Yoshikawa I and Araki K $2007 \mathrm{~J}$. Am. Chem. Soc. 129 1520; (b) Zhang S, Qiao X, Chen Y, Wang Y, Edkins R M, Liu Z, Li H and Fang Q 2014 Org. Lett. 16 342; (c) Morales-Espinoza E G, Lijanova I V, Morales-Saavedra O G, Torres-Zuñiga V, HernandezOrtega S and Martínez-García M 2011 Molecules 16 6950; (d) Morales-Saavedra O G and Rivera E 2006 Polymer $\mathbf{4 7} 5330$

17. (a) Dong J, Wang Y, Zhang J, Zhan X, Zhu S, Yang H and Wang G 2013 Soft Matter 9 370; (b) Li W, Wang L, Zhang J-P and Wang H 2014 J. Mater. Chem. C 2 1887; (c) Etika K C, Jochum F D, Cox M A, Schattling P, Theato P and Grunlan J C 2010 Macromolecules $\mathbf{4 3}$ 9447 